\title{
VISCOSITIES AND DEVIATIONS IN VISCOSITY FOR BINARY MIXTURES OF TETRAHYDROFURAN + PROPANOL-1 AND TETRAHYDROFURAN + BUTANOL-1 AT 303.15 K
}

\author{
Ponchomi Raha1, Mahmuda Sultana', M. Kamrul Hossain ${ }^{3}$, M. Abdur Rahaman ${ }^{4}$ \\ ${ }^{1}$ Department of Chemistry, Mawlana Bhashani Science and Technology University, Tangail-1902, Bangladesh \\ ${ }^{2}$ Department of Chemistry, Mawlana Bhashani Science and Technology University, Tangail-1902, Bangladesh \\ ${ }^{3}$ Department of Basic Science, World University of Bangladesh, Dhaka-1205, Bangladesh \\ ${ }^{4}$ Department of Chemistry, Mawlana Bhashani Science and Technology University, Tangail-1902, Bangladesh
}

\begin{abstract}
The viscosities, $\eta$ of pure tetrahydrofuran, propanol-1 and butanol-1and some of their binary mixtures covering the whole composition range have been measured at temperatures $303.15 \mathrm{~K}$. From the experimental $\eta$, the deviations in viscosity ( $\Delta \eta)$ have been calculated. Excess free energy for viscous flow, $\Delta G^{\# E}$ has also been evaluated. The concentration dependences of $\eta$ were correlated to polynomial expressions, whereas, $\Delta \eta$ and $\Delta G^{\# E}$ were fitted to the Redlich-Kister equation. For all systems, $\Delta \eta$ were found to be negative in the whole range of composition with a single lobe.
\end{abstract}

Keywords: Viscosity, Tetrahydrofuran, Propanol-1, Butanol-1.

\section{INTRODUCTION}

As a transport property, application of viscosity are vast including those used in many chemical and industrial processes, such as, design of new processes and process equipments. It has also been used to understand the molecular interactions between the components [1-4]. With the increased popularity of process and reservoir simulators, there is always a need for a consistent, reliable and accurate analytical predictive method for viscosity calculations.

Now a days, binary systems containing oxygenated compounds, such as, ethers (-O-group) and alkanols (-OH group) are found to be of increasing applications. Among them Tetrahydrofuran is commonly used for the synthesis of new compounds in organic chemistry. Also, it has been found to be a super solvent because of its rapid solvent activity, minimum gelation and lower relative viscosities for resin solutions. On the other hand, alcohols are selfassociated organic liquids which are widely used as coupling and dispersing agents in the chemical, pharmaceutical and household industries and as carrier and extraction of solvent for natural products.

Previously, Gupta et al [5] and Misra et al [6] have studied the viscometric properties of the binary mixtures of tetrahydrofuran with propanol-1 and propanol-2, while Parveen et al [7] have reported on tetrahydrofuran + methanol and $+\mathrm{o}$-cresol. A good number of literature survey shows that some systematic studies are still scarce. The present investigation therefore reports on the viscosity and excess thermodynamic properties for tetrahydrofuran + propanol-1 and tetrahydrofuran + butanol-1 in the entire range of composition at $303.15 \mathrm{~K}$.

\section{EXPERIMENTAL SECTION}

Liquids with quoted purities, tetrahydrofuran (THF): $\geq 99 \%$ and butanol-1 (NBL): $\geq 99 \%$, were procured from MERCK and propanol-1 (NPL): 99.5\% from DAEJUNG. Binary mixtures of various compositions were prepared by mass mixing pure components at different proportions with the help of an electronic balance (SHIMADZU, model:ATX224) accurate up to $\pm 0.0001 \mathrm{~g}$. The Ostwald viscometer (Technico, PSL BS/U, A-type) was used to measure the viscosity $\eta$. The flow time of liquids was recorded by an electronic stopwatch reading up to $\pm 0.1 \mathrm{~s}$. The viscometer was calibrated by doubly distilled water. For all measurements a thermostatic water bath (Model: WBT400 , Spectrolab, UK) controlled up to $\pm 0.01 \mathrm{~K}$ was used. The mole fraction was accurate up to $\pm 10^{-4}$, while the uncertainty in measured $\eta$ was estimated as $\pm 2 \times 10^{-3} \mathrm{mPa}$.s. Measured $\eta$ of pure liquids are compared with reported data as tabulated in Table-1, all of which are found to be in good agreement with the reported data.

Table-1 Comparison of experimental viscosities $(\eta / \mathrm{mPa} . \mathrm{s})$ of pure liquids with literature values at $303.15 \mathrm{k}$.

\begin{tabular}{|l|l|l|}
\hline Sample & $\eta / \mathrm{mPa} . \mathrm{s}$ \\
\hline & This work & Literature \\
\hline Tetrahydrofuran & 0.4462 & $0.438^{\mathrm{a}}$ \\
\hline Propanol-1 & 1.6388 & $1.718^{\mathrm{b}}$ \\
\hline Butanol-1 & 2.2695 & $2.268^{\mathrm{b}}$ \\
\hline
\end{tabular}

${ }^{\mathrm{a}}$ Ref-[8], ${ }^{\mathrm{b}} \operatorname{Ref}-[9]$ 


\section{RESULTS AND DISCUSSION}

\subsection{Viscosities}

Viscosities, $\eta$, of THF + NPL and THF + NBL in the range $0 \leq x_{2} \leq 1$ composition measured at $303.15 \mathrm{~K}$ are as summarized in Table 2. At a particular temperature $\eta$ values were fitted to a four-degree polynomial equation of the form:

$$
\eta / m P a \cdot S=\sum_{i=0}^{n} a_{i} x_{2}^{i}
$$

where, $a_{i}$ is the coefficient of polynomial equation. Fig-1 indicates the comparative diagram of $\eta$ against $x_{2}$ of the two systems at temperatures $303.15 \mathrm{~K}$. The $\eta$ of pure liquids varies in the order: NBL > NPL > THF. For the binary mixtures, $\eta$ increases systematically as the concentration of the alcohols $x_{2}$ increases and the order of increment follows: $\mathrm{THF}+\mathrm{NBL}>\mathrm{THF}+\mathrm{NPL}$.

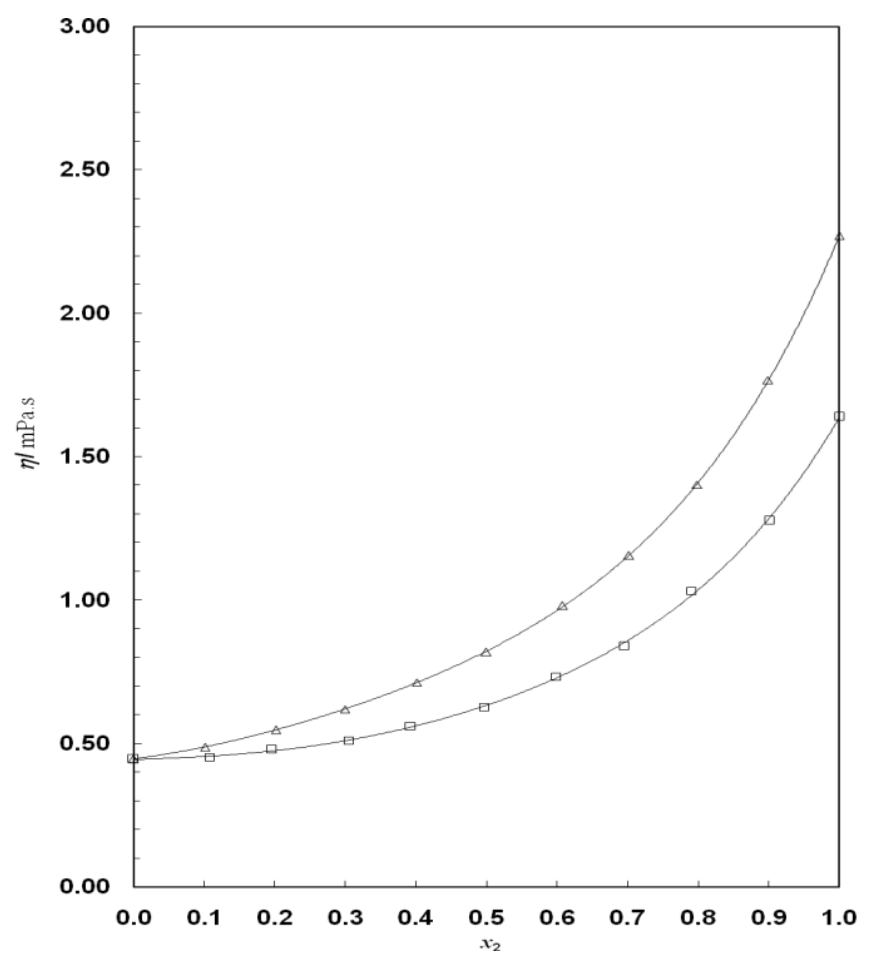

Fig-1. Comparison of viscosity, $\eta$ as a function of $x_{2}$ for the systems of THF $\left(x_{1}\right)+\operatorname{NPL}\left(x_{2}\right)(\square)$ and THF $\left(x_{1}\right)+$ NBL

$$
\left(x_{2}\right)(\Delta) \text { at } 303.15 \mathrm{~K}
$$

\subsection{Deviations in Viscosity}

From experimental $\eta$, deviations in viscosity, $\Delta \eta$ for the mixtures were calculated as [10-11]:

$$
\Delta \eta=\eta-\eta_{1} x_{1}-\eta_{2} x_{2}
$$

where, $\eta$ is the viscosity of solution, $\eta_{1}$ and $\eta_{2}$ are viscosities and $x_{1}$ and $x_{2}$ are the mole fractions of pure components 1 and 2 , respectively. The estimated values of $\Delta \eta$ were correlated well by the Redlich-Kister equation [12]:

$$
\Delta \eta=x_{2}\left(1-x_{2}\right) \sum_{i=0}^{n} A_{i}\left(2 x_{2}-1\right)^{i}
$$

where, $A_{i}$ is the fitting coefficient and $x_{2}$ is the mole fraction of the alcohols. The standard deviation, $\sigma$, followed the equation:

$$
\sigma=\left[\frac{\sum\left(\Delta \eta_{o b s}-\Delta \eta_{c a l}\right)^{2}}{n-p-2}\right]^{\frac{1}{2}}
$$

where, $\Delta \eta_{o b s}$ and $\Delta \eta_{c a l}$ are the observed and calculated deviations in viscosity, $n$ is the total number of compositions and $p$ is the number of coefficients. The coefficients, $A_{i}$ and $\sigma$ are as shown in Table 4. Fig. 2 represents the comparative diagram of $\Delta \eta$ against $x_{2}$ at $303.15 \mathrm{~K}$. For all systems, $\Delta \eta$ were negative in the whole range of composition forming a single lobe with minima at $x_{2} \sim 0.7$ for $\mathrm{THF}+\mathrm{NPL}$ and $x_{2} \sim 0.6$ for $\mathrm{THF}+\mathrm{NBL}$ systems. At a particular temperature, $\Delta \eta$ varied in the order: THF $+\mathrm{NBL}$ $>$ THF + NPL. Similar results of negative $\Delta \eta$ in THF + NPL system at $303.15 \mathrm{~K}$ were observed previously by Gupta et al. [5]. Also, same types of trend are found for THF + MNL (Methanol) by [7].

On mixing of components as fast as structures are broken down, some new H-bonds between alcohols with THF (O$\mathrm{H}---\mathrm{O}$ type) are formed simultaneously. During flow, possibly they take more favorable geometrical shapes, and thus enhance the decrement in $\eta$ values. Thus, the breaking of self-association of alcohols has influences in the deviations in viscosity, thereby suggesting that dispersive forces are operative in THF + NPL and THF + NBL systems exhibiting negative values of $\Delta \eta$. This explanation has been supported from many workers [13-14] where negative values of $\Delta \eta$ indicate dispersive interactions.

One parameter correlating equations given by Grunberg and Nissan [15] has been used to correlate the viscosity of liquid mixtures.

$$
\ln \eta=x_{1} \ln \eta_{1}+x_{2} \ln \eta_{2}+x_{1} x_{2} \varepsilon
$$

where $\varepsilon$ is a parameter proportional to the interchange energy. All the values of $\varepsilon$ are negative for both the systems as listed in Table 2 and their magnitude increases with the rise of temperature. According to Fort and Moore [16], $\varepsilon$ is termed as an approximate index for estimating strength of interaction between dissimilar components in flow. If $\Delta \eta<0$ and $\varepsilon<0$ and their magnitudes are large, specific interaction would be absent or only dispersion forces would dominant. 


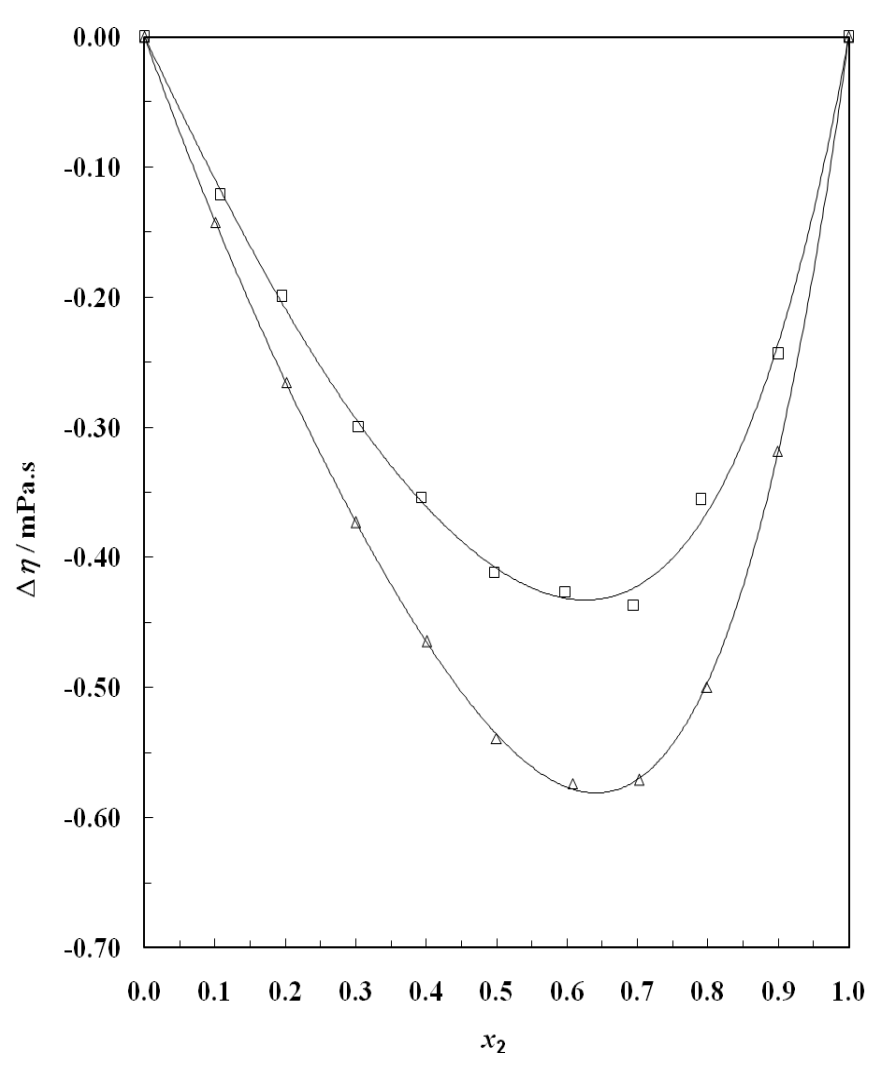

Fig-2. Comparative diagrams of deviation in viscosity, $\Delta \eta$ as a function of $x_{2}$ for the systems of THF $\left(x_{1}\right)+\operatorname{NPL}\left(x_{2}\right)$

$(\square)$ and THF $\left(x_{1}\right)+\operatorname{NBL}\left(x_{2}\right)(\Delta)$ at $303.15 \mathrm{~K}$.

Table-2 Viscosities, $\eta$ (mPa.s) and interaction parameter $(\varepsilon)$ of the systems of THF $\left(x_{1}\right)+\operatorname{NPL}\left(x_{2}\right)$ and THF $\left(x_{1}\right)+$ $\operatorname{NBL}\left(x_{2}\right)$ at different molar ratios at $303.15 \mathrm{~K}$.

\begin{tabular}{|c|c|c|c|c|c|}
\hline$x_{2}$ & $\eta$ & $\varepsilon$ & $x_{2}$ & $\eta$ & $\varepsilon$ \\
\hline \multicolumn{3}{|c|}{$\operatorname{THF}\left(x_{1}\right)+\operatorname{NPL}\left(x_{2}\right)$} & \multicolumn{3}{|c|}{$\operatorname{THF}\left(x_{1}\right)+\operatorname{NBL}\left(x_{2}\right)$} \\
\hline 0.0000 & 0.4462 & 0.0000 & 0.0000 & 0.4462 & 0.0000 \\
\hline 0.1071 & 0.4524 & -0.0151 & 0.1007 & 0.4871 & -0.0085 \\
\hline 0.1953 & 0.4796 & -0.0441 & 0.2013 & 0.5479 & -0.0308 \\
\hline 0.3048 & 0.5105 & -0.1148 & 0.2996 & 0.6195 & -0.0681 \\
\hline 0.3929 & 0.5611 & -0.1825 & 0.4011 & 0.7129 & -0.1231 \\
\hline 0.4967 & 0.6274 & -0.3014 & 0.4996 & 0.8181 & -0.2061 \\
\hline 0.5981 & 0.7331 & -0.4190 & 0.6077 & 0.9803 & -0.3119 \\
\hline 0.6949 & 0.8385 & -0.6222 & 0.7019 & 1.1551 & -0.4485 \\
\hline 0.7900 & 1.0328 & -0.7091 & 0.7987 & 1.4028 & -0.6097 \\
\hline 0.9007 & 1.2765 & -1.0944 & 0.8991 & 1.7671 & -0.7672 \\
\hline 1.0000 & 1.6388 & 0.0000 & 1.0000 & 2.2695 & 0.0000 \\
\hline
\end{tabular}

Table-3 Coefficients, $a_{i}$ of polynomial equation (1) for viscosity, $\eta$ (mPa.s) of the systems of THF $\left(x_{1}\right)+$ NPL $\left(x_{2}\right)$ and THF $\left(x_{1}\right)+\mathrm{NBL}\left(x_{2}\right)$ at $303.15 \mathrm{~K}$

\begin{tabular}{|l|l|l|l|l|l|l|}
\hline$a_{0}$ & $a_{1}$ & $a_{2}$ & $a_{3}$ & $a_{4}$ & $a_{5}$ & $\mathrm{R}^{2}$ \\
\hline $\operatorname{THF}\left(x_{1}\right)+\mathrm{NPL}\left(x_{2}\right)$ & \\
\hline 0.446 & 0.307 & 1.114 & -0.874 & 0.411 & 0.865 & 1.000 \\
\hline $\operatorname{THF}\left(x_{1}\right)+\mathrm{NBL}\left(x_{2}\right)$ \\
\hline 0.445 & 0.084 & 0.044 & 1.970 & -2.643 & 1.734 & 0.999 \\
\hline
\end{tabular}

Table-4 Polynomial fitting coefficients using equation (3) of $\Delta \eta / \mathrm{mPa}$.s and $\Delta G^{\# E} / \mathrm{kJ} \mathrm{mol}^{-1}$ and standard deviations, $\sigma$ in equation (4) for the systems of THF $\left(x_{1}\right)+\operatorname{NPL}\left(x_{2}\right)$ and $\operatorname{THF}\left(x_{1}\right)+\operatorname{NBL}\left(x_{2}\right)$ at $303.15 \mathrm{~K}$.

\begin{tabular}{|l|l|l|l|l|l|}
\hline Property & $\mathrm{A}_{0}$ & $\mathrm{~A}_{1}$ & $\mathrm{~A}_{2}$ & $\mathrm{~A}_{3}$ & $\sigma$ \\
\hline \multicolumn{5}{|l|}{$\mathrm{THF}\left(x_{1}\right)+\operatorname{NPL}\left(x_{2}\right)$} & \\
\hline$\Delta \eta$ & -1.6332 & -0.7281 & -0.4388 & -0.2267 & 0.0116 \\
\hline$\Delta G^{\# E}$ & -2.9342 & -0.0373 & -0.1085 & -0.0726 & 0.0336 \\
\hline \multicolumn{7}{|l|}{$\mathrm{THF}\left(x_{1}\right)+\operatorname{NBL}\left(x_{2}\right)$} \\
\hline$\Delta \eta$ & -2.1440 & -1.1630 & -0.6416 & -0.1046 & 0.0030 \\
\hline$\Delta G^{\# E}$ & -2.0041 & -0.5756 & -0.3393 & 0.5315 & 0.0075 \\
\hline
\end{tabular}

\subsection{Excess Free Energy}

Excess free energy for viscous flow, $\Delta G^{\# E}$ is conveniently considered as a real index for estimating the energy barrier for activating in viscous flow. It is calculated by using the equation [17]

$$
\Delta G^{\# E}=R T\left[\ln \eta V-\sum x_{i} \ln \left(\eta_{i} V_{i}\right)\right]
$$

Here, $\eta, V, \eta_{i}$ and $V_{i}$, denote the viscosity and molar volume of the mixture and pure components, respectively, and $R$ is the gas constant and $T$ is the experimental temperature. Fig.3 represents the comparative diagram of $\Delta G^{\# E}$ against $x_{2}$ at $303.15 \mathrm{~K}$. For the present systems the fact $\Delta G^{\# E}$ are all negative in the whole range of composition, leads to suggest that irrespective of volume expansion and contraction, all the flowing species surpass smaller energy barriers than it is expected from additivity rule. 


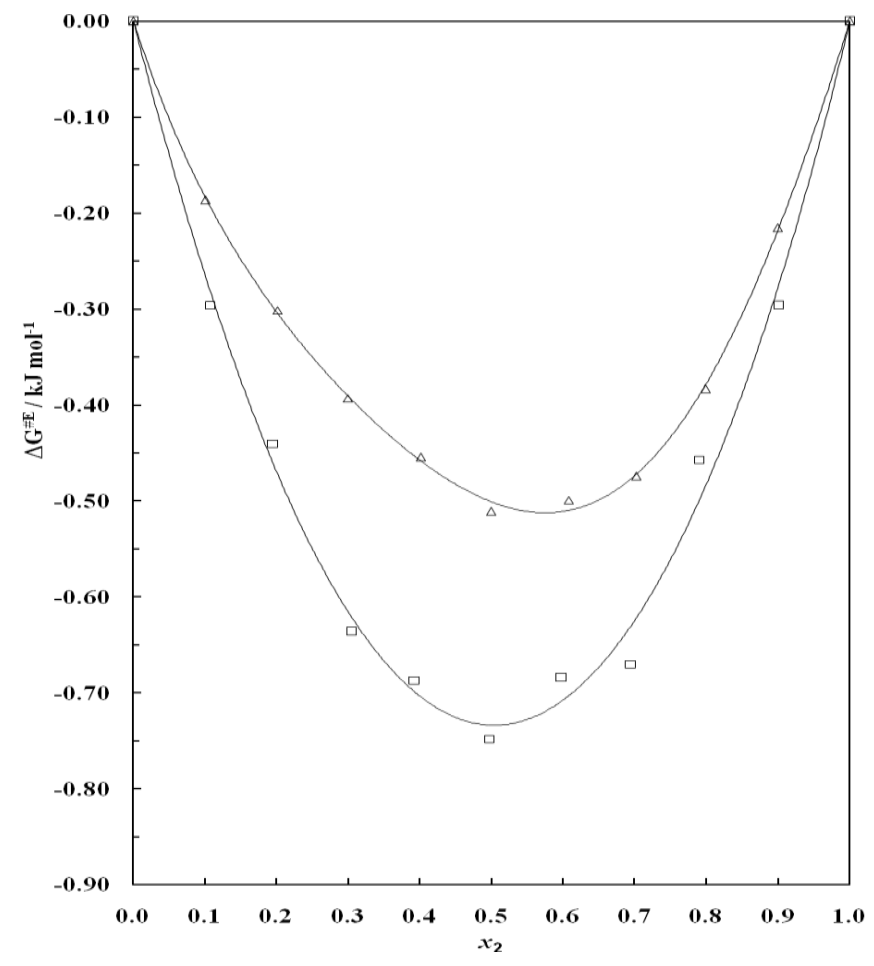

Fig-3 Comparison of excess free energies of activation for viscous flow, $\Delta G^{\# E}$ as a function of $x_{2}$ for the systems of $\operatorname{THF}\left(x_{1}\right)+\operatorname{NPL}\left(x_{2}\right)(\square)$ and THF $\left(x_{1}\right)+\operatorname{NBL}\left(x_{2}\right)(\Delta)$ at $303.15 \mathrm{~K}$.

\section{CONCLUSION}

The present study reports on measurements of viscosity, $\eta$ for the tetrahydrofuran + alcanols- 1 systems at compositions $0 \leq x_{2} \leq 1$ and at 303.15K. From measured $\eta$ the interaction parameter $\varepsilon$ and deviations $\Delta \eta$ were also calculated. In order to obtain relevant coefficients and the standard deviations, concentration dependences of $\eta$ was correlated to polynomial expressions, whereas, $\Delta \eta$ was fitted to the Redlich- Kister equations. An analysis of viscosity data based on the Grunberg_Nissan treatment shows that no specific interaction exists among the component molecules.

\section{ACKNOWLEDGEMENTS}

The authors are gratefully acknowledging the financial grants from the department of chemistry, Mawlana Bhashani Science and Technology University, Santosh, Tangail-1902, Bangladesh.

\section{REFERENCES}

[1] Mato J. S., Trenzado J. L., Alcalde R., Volumetric properties and viscosities of the ternary system methyl butanoate $+n$-heptane +1 -chloroctane and its binary constituents in the temperature range from 283.15 to 313.15 K, Fluid Phase Equilib., 202 (2002) 133-152.

[2] Singh S, Rattan VK, Kapoor S, Kumar R, Rampal A., Thermophysical properties of binary mixtures of cyclohexane + cyclohexanone at 298.15, 303.15 and 308.15 K, J. Chem. Eng. Data, 50 (2005) 288-292.
[3] Henni A, Naami A, Tontiwachwuthikul P., Densities, viscosities and derived functions of binary mixtures: (triethyleneglycol dimethyl ether + water) and(Nacetylmorpholine + water) from $298.15 \mathrm{~K}$ to 343.15 K, J. Chem. Eng. Data, 50 (2005) 1038-1042.

[4] Roy M. N., Sinha B., Dakua V. K., Excess molar volumes and viscosity deviations of binary liquid mixtures of 1,3-dioxane with butyl acetate, butyric acid, butylamine, and 2-butanone at $298.15 \mathrm{~K}$, J. Chem. Eng. Data, 51 (2006) 590-594.

[5] Gupta M, Vibhu I, Shukla J. P., Ultrasonic velocity, viscosity and excess properties of binary mixture of tetrahydrofuran with 1-propanol and 2-propanol, Fluid Phase Equilib., 244 (2006) 26-32.

[6] Misra A, Vibhu I, Singh R, Gupta M and Shukla J. P., Acoustic, viscometric and optical properties of binary mixtures of tetrahydrofuran with 1-propanol and 2-propanol, Physics and Chemistry of Liquids, 45(1) (2007) 93-104.

[7] Parveen S., Shukla D., Sing S., Singh K. P., Gupta M., and Shukla J. P., Ultrasonic velocity, density, viscosity and their excess parameters of the binary mixtures of tetrahydrofuran with methanol and ocresol at varying temperatures, Applied Acoustics, 70 (2009) 507-513.

[8] Oswal S. L., Gardas R. L. and Phalak R. P., Densities, speeds of sound, isentropic compressibilities, refractive indices and viscosities of binary mixtures of tetrahydrofuran with hydrocarbons at 303.15 K, J. Mol. Liq., 116 (2005) 109-118.

[9] Chen X., Hu R., Feng H., Chen L. and Lüdemann H., Intradiffusion, Density, and Viscosity Studies in Binary Liquid Systems of Acetylacetone + Alkanols at 303.15 K., J. Chem. Eng. Data, 57(9) (2012) 24012408.

[10] Yang C., Ma P, Zhou Q., Excess Molar Volumes and Viscosities of Binary Mixtures of Sulfolane with Benzene, Toluene, Ethylbenzene, p-Xylene, oXylene, and m-Xylene at 303.15 and $323.15 \mathrm{~K}$ and Atmospheric Pressure, J. Chem. Eng. Data, 49 (2004) 881-885.

[11] Li G., Chi H., Guo Y., Fang W., and Hu S., Excess Molar Volume along with Viscosity and Refractive Index for Binary Systems of Tricyclo[5.2.1.02.6]decane with Five Cycloalkanes, J. Chem. Eng. Data, 58 (2013) 3078-3086.

[12] Redlich O. J. and Kister A. T., Algebraic Representation of Thermodynamic Properties and the Classification of Solutions, Ind. Eng. Chem., 40 (1948) 345-348.

[13] Victor P. J. and Hazra D. K., Excess Molar Volumes, Viscosity Deviations, and Isentropic Compressibility Changes in Binary Mixtures of $N$-Methylacetamide + 2-Methoxyethanol and $\mathrm{N}$-Methylacetamide + Water at $(308.15,313.15$, and 318.15) K., J. Chem. Eng. Data, 47 (1) (2002) 79-82.

[14] Trenzado J. L., Matos J. S., Alcalde R., Volumetric properties and viscosities of the methyl butanoate + $n$-heptane + cyclo-octane ternary system at 283.15 
and $313.15 \mathrm{~K}$ and its binary constituents in the temperature range from 283.15 to 313.15 K., Fluid Phase Equilib., 200(2002) 295-315.

[15] Grunberg L. and Nissan A. H., Mixture Law for Viscosity, Nature 164 (1949) 799.

[16] Fort R. J. and Moore W. R., Viscosities of binary liquid mixtures, Trans Farady Soc., 62 (1966) 1112 1119.

[17] Oswal S. L., Prajapati K. D., Oswal P., Ghael N. Y., Ijardar S. P., Viscosity of binary mixtures of 1alkanol+cyclohexane, 2-alkanol+cyclohexane and 1alkanol+methylcyclohexane at $303.15 \mathrm{~K}$, J. Mol. Liq., 116 (2005) 73-82. 